\title{
CORRELATION OF THE COLOUR OF STRAW FUEL PELLETS TO THE COMPRESSIVE PROPERTIES
}

\section{KORELACIJA IZMEĐU BOJE ENERGETSKIH PELETA OD SLAME I PRITISNIH OSOBINA}

\author{
Lubomír KUBÍK, Viera KAŽIMÍROVÁ, Monika BOŽIKOVÁ, Tomáš GIERTL, Štefan MIHINA \\ Slovak University of Agriculture in Nitra, Tr. A. Hlinku 2, 94976 Nitra, Slovak Republic \\ email:Lubomir.Kubik@uniag.sk
}

\begin{abstract}
The aim of the manuscript was the evaluation of the compressive properties of straw pellets in relation to the colour differences between them. Modulus of elasticity and failure strength of the pellets at the compression were determined. A testing machine Andilog Stentor 1000 (Andilog Technologies, Vitrolles, France) was employed for uniaxial compression tests. $L^{*}$, a*, $b^{*}$ colour coordinates of CIE LAB 3D colour space were used for the characterization of the pellet's colour. Two sorts of pellets were measured: made from wheat straw and made from the mixed wheat and barley straw. Samples were measured by a spectrophotometer 3NH YS3020 and computed as the mean of twenty samples. The correlation of the pellet colour with the mechanical properties, mainly modulus of elasticity and failure strength of the pellets at the compression were realized to obtain a relation of the deformation process to the pellet's colour of different sorts of pellets.
\end{abstract}

Keywords: straw pellets, failure strength, modulus of elasticity, colour, CIE $L^{*} a * b^{*}$.

\section{REZIME}

Cilj rukopisa bio je procena pritisnih svojstava peleta od slame u odnosu na razlike u boji među njima. Određeni su moduli elastičnosti i čvrstoće loma na kompresiju. Za ispitivanje jednoosne kompresije bila je upotrebljen merni uređaj Andilog Stentor 1000 (Andilog Technologies, Vitrolles, Francuska). Koordinate boja L*, a*, b* CIE LAB 3D prostora boja korišćene su za karakterizaciju boje peleta. Ispitivane su dve vrste peleta: od pšenične slame $i$ od mešavine slame pšenice $i$ ječma. Uzorci su izmereni spektrofotometrom 3NH YS3020 i izračunati kao srednja vrednost dvadeset uzoraka. Korelacija boje peleta sa mehaničkim svojstvima, uglavnom modulom elastičnosti i naponom razaranja peleta pri pritisku, ostvarena je da bi se dobio zavisnost procesa deformacije od boje peleta različitih vrsta peleta.

Ključne reči: peleti od slame, napon razaranja, modul elastičnosti, boja, CIE $L * a * b *$.

\section{INTRODUCTION}

Mechanical properties of the fuel pellets represent very useful information of the state of the pellets during production and transport. Single pellet compressive strength was determined by Larsson and Samuelsson (2017). The compressive strength of the pellets was measured by Instron 3366 instrument. The pellets were compressed in a longitudinal direction by moving the upper Instron plate. The compression force was recorded. The definition of compressive strength was approached as the maximum of the load value during compression. Effect of moisture addition during steam conditioning of pellets on pellet quality and electrical energy consumption in a pelleting process influenced the physical properties mainly, the hardness and the durability of pellets. Pellets, produced from conditioned material with higher content of moisture, were more stable and less hard (Vukmirović et al., 2010).

Possibilities of the determination of the quality of the fuel pellets are very important for the obtaining of the material originality. Colour is the one factor describing the texture of the material. The colour of the pellets is usually very similar, and a human eye is not able to distinguish between similar colours. The spectrophotometer can determine the colour coordinates and differentiate the colours indistinguishable by the human eye.

The superficial appearance and colour of the material are the first parameters of quality evaluated by consumers and are thus critical factors for acceptance of the food or product item by the consumer. Finding a modeling (and estimate its parameters) for obtaining $L^{*} a * b *$ colour measurements from RGB measurements by the right model is very important (León et al., 2006).

Sucrose pellets with a colour coating suspension in the size range of $0.71-0.85 \mathrm{~mm}$ were tested. The colour distribution on the film coating was analyzed using a tristimulus colorimeter and the colour value was measured in CIELAB units (Chan et al., 2001). The change in pellet coloring was also tested through a spectrophotometer for both xylan and carboxymethyl cellulose pellets. The study of Frodeson et al., (2019a) postulates that the color difference of the xylan pellets is a result of physical changes in the structure, as opposed to being of chemical nature. Pegoretti et al., (2019) were interested in the correlation of the pellets' colorimetric characteristics (CIE- $L * a * b *$ ) to ash extractives content and heating values. Frodeson et al., (2019b) found out that the results have shown that xylan pellets completely changed in color at $10 \%$ moisture content, and this also occurred to some extent with pectin pellets. Pavkov et al. (2019) were interested in the measurement of the colour of the air-drying blueberry fruits measured before and after convective and freeze-drying. There was a noticeable difference in the sample brightness $\left(\Delta E^{*}\right)$ between freeze- and air-dried blueberries. Colour measuring of the colour change of quince during combined drying was performed with a three-filter 
colorimeter Konica Minolta CR-400. This instrument could express quantitative colour parameters in different systems. CIE $L^{*} a^{*} b^{*}$ colour system was selected, based on the three-filter method. The change of the value $L^{*}$, which describes sample brightness, had a similar trend to all the experimental units except for $60{ }^{\circ} \mathrm{C}$ and $50{ }^{\circ} \mathrm{Bx}$. A small decrease of the value $L^{*}$ was determined, which denotes small changes in sample brightness. The negative value $a^{*}$ expressed mostly the green colour, while the positive values expressed the red colour. For all the experimental units, the negative value was within the range of -2 to -5 . A significant increase of the value $b^{*}$ was observed in all the experiments. This fact points to the more intensive and “cleaner” yellow colour (Radojčin et al., 2010). The influence of the concentration and temperature on the colour of the apple samples, osmotically dehydrated in sugar beet molasses was investigated by Koprivica et al., (2011). The negative value of parameter $a^{*}$ (about -3 ), measured in fresh apples, during the dehydration was significantly changed and got a preceding plus sign which indicates the dominance of red colour in the treated samples $\left(a^{*}=9-13\right)$. Colour is an important indicator of product quality. The effects of different pretreatments on the pear colour alteration during and after combined drying were studied by Radojčin et al., (2013). The most significant change in the value of the internal colour $L^{*}$ parameter was recorded in the blanched samples. All the samples have shown an increase in the value of the $b^{*}$ parameter following convective drying. After the osmotic drying, the most significant change in the value of the external colour $L^{*}$ parameter was also recorded in the blanched samples.

The aim of the manuscript was to determine and distinguish the originality of two sorts of very colour-similar fuel straw pellets by the colour coordinates CIE $L^{*} a^{*} b^{*}$. The correlation of the pellet colour with the mechanical properties, mainly modulus of elasticity and failure strength of the pellets at the compression were realized to obtain a relation of the deformation process to the pellet's colour of different sorts of pellets.

\section{MATERIAL AND METHOD}

Two sorts of AGRO pellets were measured: The first was made from wheat straw and waste from the cleaning of the wheat straw pellets. The second sort was made from the mixed wheat and barley straw and waste from the cleaning of the wheat and barley (next mixed straw pellets). Also, dried grass from the maintenance of the basin of Malý Dunaj and greenness from public space of the maintenance of a village Nový Život, Senec region, Slovak Republic were mixed in the biomass of both sorts of pellets. The pellets were made by the pellet production line ProPelety AGRO Basic (ProPelety s.r.o., Czech Republic).

Statical compressive loading in the uniaxial direction was used for the pellet's samples testing. The compression was realized between two parallel plates. A testing machine Andilog Stentor 1000 (Andilog Technologies, Vitrolles, France) was employed for uniaxial compression tests. The experiments were performed at velocity $1 \mathrm{~mm}$. $\mathrm{min}^{-1}$. The force $F(\mathrm{~N})$ and the compression $D(\mathrm{~m})$ were measured by the acquisition software RSIC ver. 4.06. The stresses and the strains were calculated for the cylindrical samples in the compression loading. The loading curves of dependence of the stresses on the strains were realized. The method based on the elastic theory and Hook's law was used for the determination of the moduli of elasticity. Values of moduli of elasticity were calculated as the slope of the linear part of the stress-strain curves on the basis of the regression method. The failure strength and the failure strain were determined from the maximal values of the strain and the stress from the maximums of the loading curves.
$L^{*}, a^{*}, b^{*}$ colour coordinates of CIE LAB 3D colour space were used for the characterization of the colour straw fuel pellets. Samples were measured by a spectrophotometer (3NH YS3020, Shenzhen 3nh Technology CO., LTD, China) and computed as the mean of twenty samples. The spectrophotometer was equipped with a D65 illumination source, a $2^{\circ}$ observer angle, a diffused illumination and an $8^{\circ}$ viewing angle di: $8^{\circ}$ optical geometry. $L^{*}, a^{*}$ and $b^{*}$ were used to define a three-dimensional colour space and interpreted $L^{*}$, the lightness, the values ranging from 0 to $100, a^{*}$, redness and greenness, $b^{*}$, yellowness and blueness. Cylindrical model CIELCh or CIEHLC space is a colour space based on CIELAB, which uses the polar coordinates $C^{*}$ (chroma, relative saturation) and $h^{\circ}$ (hue angle, angle of the hue in the CIELAB colour wheel) instead of the Cartesian coordinates $a^{*}$ and $b^{*}$. The CIELAB lightness $L^{*}$ remains unchanged. Chroma or chromatic saturation $\left(C^{*}\right)$ is the purity of a colour (a high chroma has no added black, white, or gray). Saturation refers to how strong or weak a colour is (high saturation being strong). Value refers to how light or dark a colour is (light having a high value). Hue angle $\left(h^{\circ}\right)$, is the colour nuance, red-purple: 0; yellow: 90; bluish-green: 180; blue: 270. The conversion of $a^{*}$ and $b^{*}$ to $C^{*}$ and $h^{\circ}$ is performed as follows (McGuire, 1992; Gözlekçi, et al., 2011; Júnior, et al., 2016).:

$C^{*}=\left(a^{* 2}+b^{* 2}\right)^{\frac{1}{2}}$

The hue angle ( $h$ ) was calculated as follows:

$h^{\circ}=\arctan \left(\frac{b^{*}}{a^{*}}\right)$,

Table 1. Parameters of the wheat pellets. $d$-diameter of the sample, $l_{0}$ - length of the sample, $m$ - the mass of the sample, $V$ - the volume of the sample

\begin{tabular}{|c|c|c|c|c|c|}
\hline $\mathbf{n}$ & d (mm) & $\mathrm{l}_{0}(\mathrm{~mm})$ & m (g) & $\mathrm{V}\left(\mathrm{mm}^{3}\right)$ & $\begin{array}{c}\text { Bulk } \\
\text { density } \\
\left(\mathrm{kg} . \mathrm{m}^{-3}\right)\end{array}$ \\
\hline 1 & 10.60 & 37.70 & 3.00 & 3325.24 & 902.19 \\
\hline 2 & 10.50 & 29.20 & 2.40 & 2527.15 & 949.69 \\
\hline 3 & 11.10 & 28.70 & 2.32 & 2775.86 & 835.78 \\
\hline 4 & 10.68 & 33.10 & 2.89 & 2963.74 & 975.12 \\
\hline 5 & 10.78 & 22.30 & 1.98 & 2034.29 & 973.31 \\
\hline 6 & 10.68 & 22.08 & 1.88 & 1977.02 & 950.93 \\
\hline 7 & 10.72 & 24.30 & 2.02 & 2192.13 & 921.48 \\
\hline 8 & 10.68 & 24.42 & 2.10 & 2186.54 & 960.42 \\
\hline 9 & 10.70 & 23.58 & 2.10 & 2119.24 & 990.92 \\
\hline 10 & 10.68 & 14.04 & 1.10 & 1257.13 & 875.01 \\
\hline Mean & 10.712 & 25.942 & 2.179 & $\begin{array}{c}2335.83 \\
4\end{array}$ & 933.484 \\
\hline SD & 0.049 & 2.077 & 0.169 & 184.889 & 15.635 \\
\hline VC (\%) & 0.458 & 8.005 & 7.769 & 7.915 & 1.675 \\
\hline
\end{tabular}

The colour differences values $\Delta a^{*}, \Delta b^{*}$ and $\Delta L^{*}$ were determined by the spectrophotometer for the couples created of both sorts of pellets. The colour differences $\Delta E$ value for each measurement $\left(L^{*}, a^{*}, b^{*}\right)$ were calculated with respect to the initial colour on the pellets according to the following equation:

$$
\Delta E=\left(\Delta L^{*^{2}}+\Delta a *^{2}+\Delta b^{*^{2}}\right)^{1 / 2}
$$


Table 2. Parameters of the mixed pellets. $d$-diameter of the sample, $l_{0}$ - length of the sample, $m$ - the mass of the sample, $\mathrm{V}$ - the volume of the sample

\begin{tabular}{|c|c|c|c|c|c|}
\hline $\mathbf{n}$ & $\mathrm{d}(\mathrm{mm})$ & $\mathbf{l}_{0}(\mathrm{~mm})$ & m (g) & $\mathbf{V}\left(\mathbf{m m}^{3}\right)$ & $\begin{array}{c}\text { Bulk } \\
\text { density } \\
\left(\mathrm{kg} . \mathrm{m}^{-3}\right)\end{array}$ \\
\hline 1 & 13.20 & 36.30 & 4.60 & 4965.06 & 926.47 \\
\hline 2 & 13.30 & 36.10 & 4.67 & 5012.80 & 931.62 \\
\hline 3 & 12.05 & 31.15 & 3.32 & 3550.60 & 935.05 \\
\hline 4 & 13.00 & 31.25 & 3.95 & 4145.78 & 952.78 \\
\hline 5 & 12.15 & 35.10 & 3.99 & 4067.52 & 980.94 \\
\hline 6 & 12.95 & 33.25 & 3.84 & 4377.24 & 877.26 \\
\hline 7 & 13.30 & 28.15 & 3.32 & 3908.87 & 849.35 \\
\hline 8 & 12.70 & 34.20 & 3.90 & 4330.15 & 900.66 \\
\hline 9 & 13.30 & 31.20 & 3.87 & 4332.39 & 893.27 \\
\hline 10 & 13.10 & 34.70 & 4.01 & 4674.57 & 857.83 \\
\hline Mean & 12.905 & 33.140 & 3.947 & \begin{tabular}{|l|}
4336.498 \\
\end{tabular} & 910.524 \\
\hline SD & 0.147 & 0.832 & 0.140 & 144.441 & 13.360 \\
\hline VC (\%) & 1.140 & 2.512 & 3.544 & 3.331 & 1.467 \\
\hline
\end{tabular}

The statistical analysis was realized by the description statistic: mean, standard deviation, variation coefficient, minimum, maximum and median. F-test and t-test on the significant level $\alpha=0.05$ were realized to distinguish the pellet sorts. The correlation analysis was applied to obtain the correlation between the colour and mechanical parameters. The statistical calculations were realized by Microsoft Excel 365.

\section{RESULTS AND DISCUSSION}

The parameters of the wheat and mixed pellet samples are shown in Table 1 and Table 2. The dependences of the stress on the strain were realized for ten samples of the loading speed

$1 \mathrm{~mm} . \mathrm{min}^{-1}$. The compression diagram of the wheat straw pellet sample no. 1 is shown in Fig. 1. The stress-strain curves were characterized by the peaks which represent the limit of the firmness of straw pellet samples. The failure strain and failure strength were determined in the peaks. Determination of the modulus of elasticity of the wheat straw pellets sample no. 1 at the loading speed $1 \mathrm{~mm} . \mathrm{min}^{-1}$ between two parallel plates is presented in Fig 2.

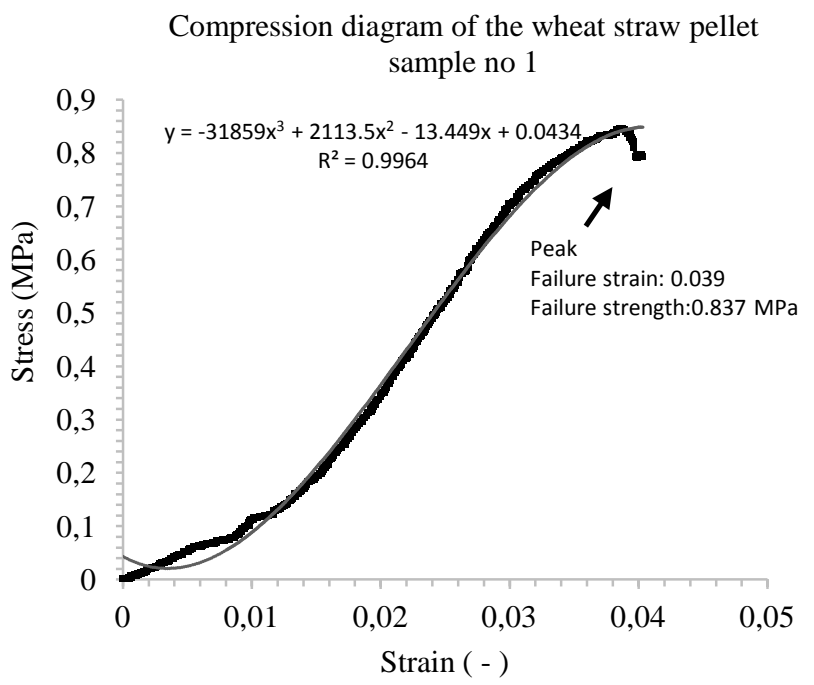

Fig. 1. Compression diagrams - of the wheat straw pellets sample no. 1 at the loading speed $1 \mathrm{~mm} \cdot \mathrm{min}^{-1}$ between two parallel plates
The compression diagram of the mixed straw pellet sample no. 3 is shown in Fig. 3. The stress-strain curves were characterized by the peaks which represent the limit of the firmness of straw pellet samples. The failure strain and failure strength were determined in the peaks. Determination of the modulus of elasticity of the wheat straw pellets sample no. 3 at the loading speed $1 \mathrm{~mm} . \mathrm{min}^{-1}$ between two parallel plates is presented in Fig 4.

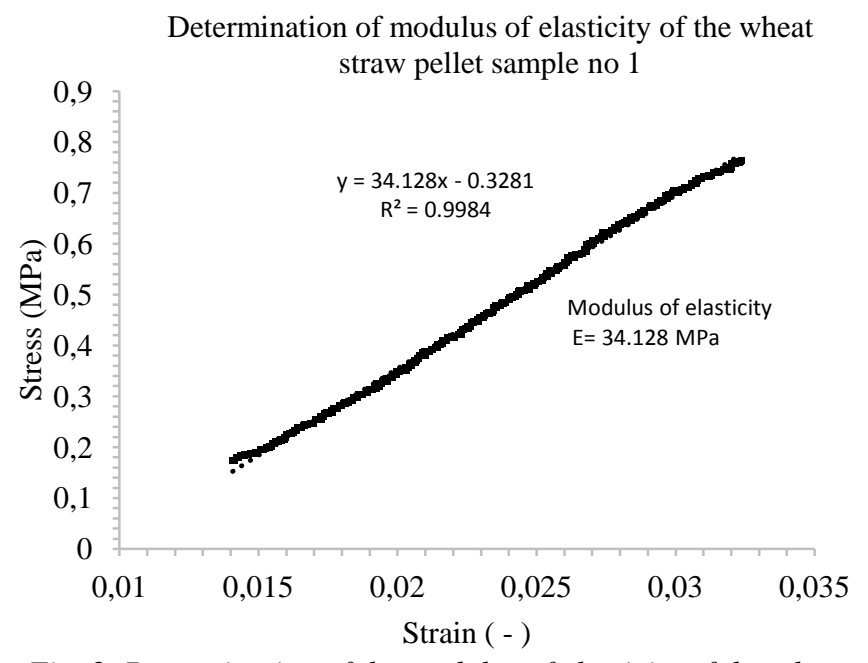

Fig. 2. Determination of the modulus of elasticity of the wheat straw pellets sample no. 1 at the loading speed $1 \mathrm{~mm} \cdot \mathrm{min}^{-1}$ between two parallel plates

Compression diagram of the mixed straw pellet sample no 3

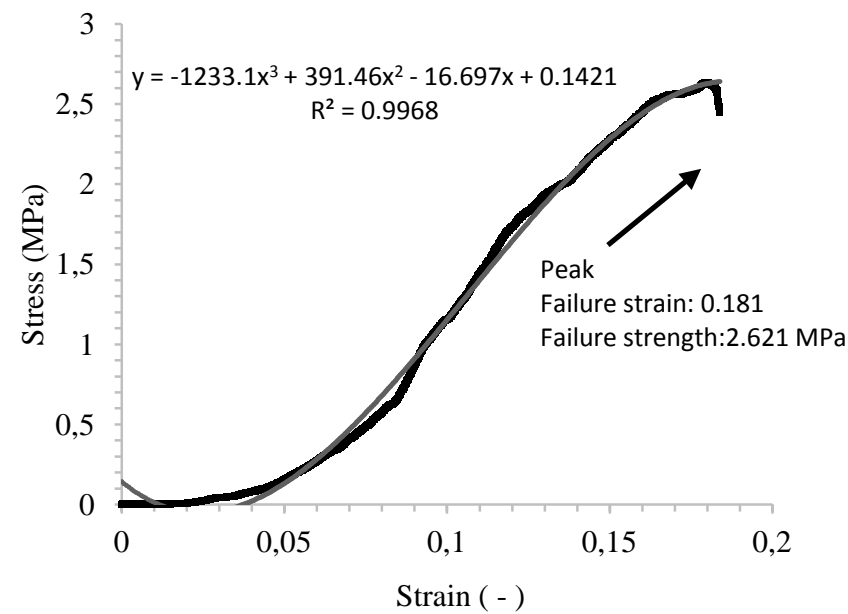

Fig. 3. Compression diagrams - of the wheat straw pellets sample no. 3 at the loading speed

$1 \mathrm{~mm} \cdot \mathrm{min}^{-1}$ between two parallel plates

Compressive parameters of the wheat and mixed pellet samples are shown in Tables 3 and 4 . The correlation of the compressive parameters can see in Table 5. A strong correlation at the significant level 0.05 was achieved between compression parameters EM - FSW, FSM - F SW, FSM - FSTW, FSW FSTW, FSM - FSTM and EM - FSM. (where FSM - failure strength, FSTM - failure strain, EM - modulus of elasticity, FSW - failure strength, FSTW - failure strain, EW - modulus of elasticity). Modulus of mixed pellets correlated with the failure strength of the mixed, but also the wheat pellets (EM - FSW, EM - FSM). Failure strength of mixed pellets correlated with the failure strength of the wheat pellets and with failure strain of the wheat and mixed pellets (FSM - FSW, FSM - FSTW and FSM - FSTM). Failure strength of the wheat pellets correlated with the failure strain of the wheat pellets (FSW - FSTW). 


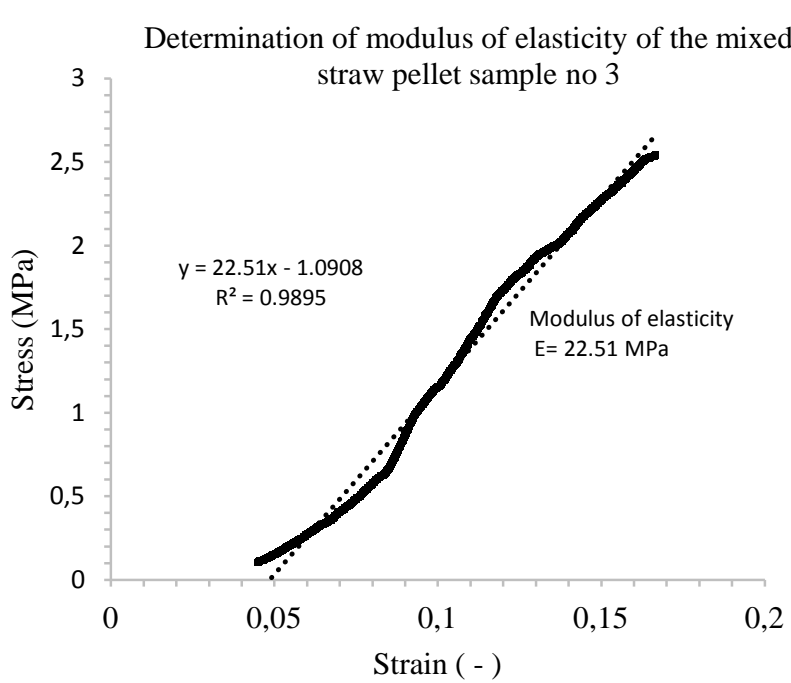

Fig. 4. Determination of the modulus of elasticity of the mixed straw pellets samples no. 3 at the loading speed $1 \mathrm{~mm} \cdot \mathrm{min}^{-1}$ between two parallel plates

Table 3. Compressive parameters of the wheat pellet samples at speed $1 \mathrm{~mm} \cdot \mathrm{min}^{-1}$. SD - standard deviation, VC - coefficient of variation

\begin{tabular}{||c|c|c|c||}
\hline \hline $\mathbf{n}$ & $\begin{array}{c}\text { Failure strain } \\
(-\mathbf{~}\end{array}$ & $\begin{array}{c}\text { Failure } \\
\text { strength } \\
\mathbf{( M P a )}\end{array}$ & $\begin{array}{c}\text { Modulus of } \\
\text { elasticity } \\
\text { (MPa) }\end{array}$ \\
\hline 1 & 0.039 & 0.837 & 34.128 \\
\hline 2 & 0.121 & 2.970 & 38.895 \\
\hline 3 & 0.197 & 3.077 & 26.562 \\
\hline 4 & 0.063 & 1.624 & 34.413 \\
\hline 5 & 0.162 & 3.056 & 24.959 \\
\hline 6 & 0.178 & 2.984 & 26.306 \\
\hline 7 & 0.170 & 1.228 & 11.254 \\
\hline 8 & 0.110 & 1.868 & 23.872 \\
\hline 9 & 0.211 & 4.577 & 34.935 \\
\hline 10 & 0.105 & 0.945 & 11.473 \\
\hline Mean & 0.136 & 2.317 & 26.680 \\
\hline SD & 0.018 & 0.381 & 3.005 \\
\hline VC (\%) & 13.361 & 16.433 & 11.264 \\
\hline
\end{tabular}

Table 4. Compressive parameters of the mixed pellet samples at speed $1 \mathrm{~mm} \cdot \mathrm{min}^{-1}$. SD - standard deviation, $\mathrm{VC}$-coefficient of variation

\begin{tabular}{|c|c|c|c||}
\hline $\mathbf{n}$ & $\begin{array}{c}\text { Failure } \\
\text { strain } \\
(-)\end{array}$ & $\begin{array}{c}\text { Failure } \\
\text { strength } \\
\text { (MPa) }\end{array}$ & $\begin{array}{c}\text { Modulus of } \\
\text { elasticity } \\
\text { (MPa) }\end{array}$ \\
\hline 1 & 0.120 & 1.543 & 21.190 \\
\hline 2 & 0.113 & 2.230 & 29.585 \\
\hline 3 & 0.181 & 2.621 & 22.510 \\
\hline 4 & 0.107 & 1.084 & 21.928 \\
\hline 5 & 0.102 & 2.411 & 30.925 \\
\hline 6 & 0.119 & 2.031 & 26.944 \\
\hline 7 & 0.145 & 1.899 & 21.786 \\
\hline 8 & 0.079 & 1.366 & 24.537 \\
\hline 9 & 0.159 & 2.957 & 29.918 \\
\hline 10 & 0.043 & 0.630 & 18.847 \\
\hline Mean & 0.117 & 1.877 & 24.817 \\
\hline SD & 0.012 & 0.229 & 1.343 \\
\hline VC (\%) & 10.647 & 12.187 & 5.411 \\
\hline
\end{tabular}

Table 5. Correlation between measured parameters, FSM failure strength, FSTM - failure strain, EM - modulus of elasticity, FSW - failure strength, FSTW - failure strain, EW modulus of elasticity, $W$ - wheat straw pellets, $M$ - mixed straw pellets

\begin{tabular}{|c|c|c|c|c|c|c||}
\hline & FSTW & FSW & EW & FSTM & FSM & EM \\
\hline & 1 & & & & & \\
\hline FSW & $\mathbf{0 . 7 4 9}$ & 1 & & & & \\
\hline EW & -0.183 & 0.462 & 1 & & & \\
\hline FSTM & $\mathbf{0 . 5 6 6}$ & $\mathbf{0 . 5 2 1}$ & 0.315 & 1 & & \\
\hline FSM & $\mathbf{0 . 7 6 2}$ & $\mathbf{0 . 8 5 4}$ & 0.381 & $\mathbf{0 . 7 9 3}$ & 1 & \\
\hline EM & 0.489 & $\mathbf{0 . 8 2 2}$ & 0.491 & 0.230 & $\mathbf{0 . 7 2 6}$ & 1 \\
\hline
\end{tabular}

The results of the pellet colour parameters of the wheat straw pellets are shown in Table 6 and of the mixed pellets in Table 7. Chromatic saturation $C^{*}$ and hue $h^{\circ}$ were calculated from equations (1) and (2).

Table 6. Wheat straw pellet colour parameters $L^{*}, a^{*}, b^{*}-$ colour coordinates; $h^{\circ}$ - hue angle; $C^{*}$ - chroma; SD - standard deviation; $\mathrm{CV}$ - coefficient of variation.

\begin{tabular}{||c|c|c|c|c|c||}
\hline Wheat straw & $\mathbf{L}^{*}$ & $\mathbf{a}^{*}$ & $\mathbf{b}^{*}$ & $\mathbf{h}^{\circ}$ & $\mathbf{C}^{*}$ \\
\hline 1 & 58.82 & 3.07 & 20.26 & 81.27 & 20.49 \\
\hline 2 & 56.57 & 3.45 & 21.25 & 80.67 & 21.53 \\
\hline 4 & 53.51 & 4.26 & 20.59 & 78.20 & 21.03 \\
\hline 5 & 55.69 & 3.82 & 21.23 & 79.69 & 21.57 \\
\hline 6 & 60.46 & 3.04 & 22.87 & 82.32 & 23.07 \\
\hline 7 & 54.50 & 3.26 & 21.70 & 81.34 & 21.94 \\
\hline 8 & 48.52 & 4.70 & 21.03 & 77.30 & 21.55 \\
\hline 9 & 56.31 & 3.98 & 23.42 & 80.25 & 23.76 \\
\hline 10 & 55.49 & 4.40 & 23.67 & 79.36 & 24.08 \\
\hline 11 & 55.47 & 4.45 & 23.23 & 79.05 & 23.65 \\
\hline 12 & 59.80 & 4.13 & 23.50 & 79.92 & 23.86 \\
\hline 13 & 54.80 & 3.77 & 22.23 & 80.26 & 22.55 \\
\hline 14 & 56.00 & 4.71 & 23.25 & 78.44 & 23.72 \\
\hline 15 & 54.15 & 4.35 & 23.15 & 79.25 & 23.56 \\
\hline 16 & 50.21 & 4.36 & 22.64 & 78.99 & 23.06 \\
\hline 17 & 52.99 & 4.79 & 21.88 & 77.55 & 22.40 \\
\hline 18 & 54.85 & 4.51 & 21.94 & 78.28 & 22.40 \\
\hline 19 & 53.17 & 4.08 & 20.00 & 78.36 & 20.41 \\
\hline 20 & 56.45 & 4.39 & 23.03 & 79.10 & 23.44 \\
\hline Mean & 55.279 & 4.106 & 22.186 & 79.405 & 22.568 \\
\hline SD & 0.641 & 0.121 & 0.256 & 0.295 & 0.259 \\
\hline VC (\%) & 1.160 & 2.955 & 1.155 & 0.371 & 1.149 \\
\hline Minimum & 48.520 & 3.040 & 20.000 & 77.296 & 20.412 \\
\hline Maximum & 60.460 & 4.790 & 23.670 & 82.315 & 24.075 \\
\hline Median & 57.635 & 3.730 & 21.645 & 80.186 & 21.968 \\
\hline \hline
\end{tabular}

$\mathrm{F}$ - tests of the variations of the quantities between the wheat and mixed pellets were realized on the significant level $\alpha=0.05$ to find out if the variations are the same. T-tests for the equal or unequal variations were then selected. T-tests on the significant level 0.05 were realized to distinguish the means of the colour coordinates $L^{*}, a^{*}, b^{*}$ and chroma $C^{*}$ and hue $h^{\circ}$ to distinguish the pellet sorts. The null hypothesis of the $\mathrm{F}$ - tests and the t-tests were that the two population variations or means are equal. An alternative hypothesis was, the two population means are not equal. If the $p$-value is less than the significance level (0.05), we can reject the null hypothesis. The difference between the two variations or means is statistically significant. The $p$ probability of the statistical tests of the variations and the means colours parameters are shown in Table 8. 
Kubík, Lubomír et al./ Correlation of the Colour of Straw Fuel Pellets to the Compressive Properties

Table 7. Mixed straw pellet colour parameters. $L^{*}, a^{*}, b^{*}-$ colour coordinates; $h^{\circ}$ - hue angle; $C^{*}$ - chroma; $S D$ - standard deviation; $C V$ - coefficient of variation

\begin{tabular}{|c|c|c|c|c|c||}
\hline Mixed straw & $\mathbf{L}^{*}$ & $\mathbf{a}^{*}$ & $\mathbf{b}^{*}$ & $\mathbf{h}^{\circ}$ & $\mathbf{C}^{*}$ \\
\hline 1 & 59.97 & 3.08 & 18.61 & 80.49 & 18.86 \\
\hline 2 & 59.59 & 3.37 & 19.49 & 80.08 & 19.78 \\
\hline 3 & 58.73 & 3.30 & 16.85 & 78.81 & 17.17 \\
\hline 4 & 63.84 & 3.85 & 21.11 & 79.56 & 21.46 \\
\hline 5 & 62.04 & 3.90 & 24.18 & 80.73 & 24.49 \\
\hline 6 & 66.36 & 2.51 & 25.93 & 84.36 & 26.05 \\
\hline 7 & 55.61 & 4.05 & 19.83 & 78.35 & 20.24 \\
\hline 8 & 56.03 & 2.90 & 18.91 & 81.17 & 19.13 \\
\hline 9 & 52.65 & 3.27 & 19.30 & 80.27 & 19.58 \\
\hline 10 & 64.36 & 2.27 & 20.83 & 83.67 & 20.95 \\
\hline 11 & 62.62 & 4.58 & 24.45 & 79.28 & 24.88 \\
\hline 12 & 62.26 & 3.15 & 20.77 & 81.26 & 21.01 \\
\hline 13 & 59.14 & 4.33 & 22.84 & 79.16 & 23.25 \\
\hline 14 & 63.59 & 4.04 & 23.89 & 80.29 & 24.23 \\
\hline 15 & 58.86 & 3.01 & 20.39 & 81.49 & 20.61 \\
\hline 16 & 53.76 & 3.19 & 20.98 & 81.24 & 21.22 \\
\hline $\mathbf{1 7}$ & $\mathbf{4 6 . 1 8}$ & $\mathbf{3 . 4 7}$ & $\mathbf{1 7 . 0 5}$ & $\mathbf{7 8 . 3 9}$ & $\mathbf{1 7 . 4 0}$ \\
\hline 18 & 66.76 & 2.43 & 21.20 & 83.35 & 21.34 \\
\hline 19 & 58.77 & 4.11 & 21.04 & 78.84 & 21.44 \\
\hline 20 & 59.27 & 4.45 & 21.57 & 78.24 & 22.02 \\
\hline Mean & 59.520 & 3.463 & 20.961 & 80.451 & 21.255 \\
\hline SD & 1.111 & 0.152 & 0.534 & 0.397 & 0.534 \\
\hline VC (\%) & 1.867 & 4.375 & 2.547 & 0.493 & 2.514 \\
\hline Minimum & 46.180 & 2.270 & 16.850 & 78.236 & 17.170 \\
\hline Maximum & 66.760 & 4.580 & 25.930 & 84.355 & 26.051 \\
\hline Median & 59.620 & 3.765 & 20.090 & 79.364 & 20.444 \\
\hline & & & & & \\
\hline
\end{tabular}

The variation of $L^{*}, b^{*}$ and $C^{*}$ were significantly different. A T-test of unequal variances was used for these parameters. The means of all parameters were significantly different. A Ttest of unequal variances was used for all parameters. The comparison of the colour parameters is presented in Fig. 5. The values of the parameters were very similar but statistically different. The colour differences are shown in Table 9. The colour differences $\Delta a^{*}, \Delta b^{*}, \Delta L^{*}$ and $\Delta E^{*}$ were measured directly by the spectrophotometer. The comparison of the colour parameter differences is presented in Fig. 6.

Table 8. Probability of the statistical tests of the variations and the means of the colour parameters. $p$ - probability, when $p<0.05$ the variation (F-test) or the means (t-test) are different

\begin{tabular}{|c|c|c|c|c|c||}
\hline $\mathbf{F}$-test & $\mathbf{L}^{*}$ & $\mathbf{a}^{*}$ & $\mathbf{b}^{*}$ & $\mathbf{h}^{\circ}$ & $\mathbf{C}^{*}$ \\
\hline $\mathbf{p}$ & 0.010 & 0.171 & 0.001 & 0.102 & 0.001 \\
\hline $\mathbf{t}$-test & $\mathrm{L}^{*}$ & $\mathrm{a}^{*}$ & $\mathrm{~b}^{*}$ & $\mathrm{~h}^{\circ}$ & $\mathrm{C}^{*}$ \\
\hline $\mathbf{p}$ & 0.002 & 0.002 & 0.048 & 0.041 & 0.036 \\
\hline
\end{tabular}

The correlation of the compressive parameters with the colour parameters is shown in Tables 10 and 11. The moderate positive and negative correlation at the significant level 0.05 was achieved between compression parameter modulus of elasticity of the wheat pellets and the colour parameter $L^{*}$ and $a^{*}$ of the wheat pellets in Table 10 and the negative moderate correlation was achieved between failure strain of the mixed pellets and the colour parameter $h^{\circ}$ of the mixed pellets.

Table 9. Straw pellets colour differences. $n$ - number of samples; $\Delta L^{*}, \Delta a^{*}, \Delta b^{*}, \Delta E$ - colour differences; $S D$ - standard deviation; $\mathrm{CV}$ - coefficient of variation

\begin{tabular}{|c|c|c|c|c|}
\hline $\mathbf{n}$ & $\Delta \mathrm{L}^{*}$ & $\Delta \mathrm{a}^{*}$ & $\Delta \mathrm{b}^{*}$ & $\Delta \mathrm{E}$ \\
\hline 1 & 1.15 & 0.01 & -1.65 & 2.01 \\
\hline 2 & 3.02 & -0.08 & -1.76 & 3.5 \\
\hline 3 & 5.22 & -0.96 & -3.74 & 6.5 \\
\hline 4 & 8.15 & 0.03 & -0.12 & 8.14 \\
\hline 5 & 1.58 & 0.86 & 1.31 & 2.23 \\
\hline 6 & 11.86 & -0.85 & 4.23 & 12.62 \\
\hline 7 & 7.09 & -0.65 & -1.2 & 7.21 \\
\hline 8 & -0.28 & -1.08 & -4.51 & 4.65 \\
\hline 9 & -4.84 & -1.13 & -4.37 & 6.61 \\
\hline 10 & 8.55 & -2.18 & -2.4 & 9.14 \\
\hline 11 & 7.15 & -0.02 & 1.61 & 7.34 \\
\hline 12 & 2.46 & -0.98 & -2.73 & 3.8 \\
\hline 13 & 4.34 & 0.56 & 0.61 & 4.42 \\
\hline 14 & 7.49 & -0.67 & 0.64 & 7.55 \\
\hline 15 & 4.51 & -1.34 & -2.76 & 5.45 \\
\hline 16 & 3.55 & -1.17 & -1.66 & 4.1 \\
\hline 17 & -6.81 & -1.32 & -4.83 & 8.45 \\
\hline 18 & 11.91 & -2.08 & -0.74 & 12.12 \\
\hline 19 & 5.6 & 0.03 & 1.04 & 5.69 \\
\hline 20 & 2.82 & 0.06 & -1.46 & 3.17 \\
\hline Mean & 5.419 & 0.803 & 2.169 & 6.235 \\
\hline SD & 1.063 & 0.182 & 0.524 & 0.658 \\
\hline VC (\%) & 19.620 & 22.652 & 24.168 & 10.551 \\
\hline Minimum & -6.810 & -2.180 & -4.830 & 2.010 \\
\hline Maximum & 11.910 & 0.860 & 4.230 & 12.620 \\
\hline Median & 1.985 & 0.035 & -1.555 & 2.590 \\
\hline & & & & \\
\hline
\end{tabular}

Comparison of the colour parameters

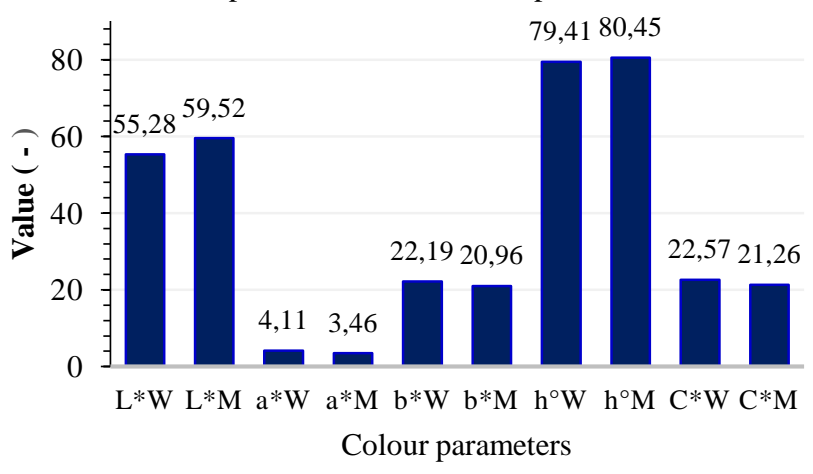

Fig. 5. Comparison of colour parameters. $W$ - wheat straw, $M$ - mixed straw

Colour differences of the pellets

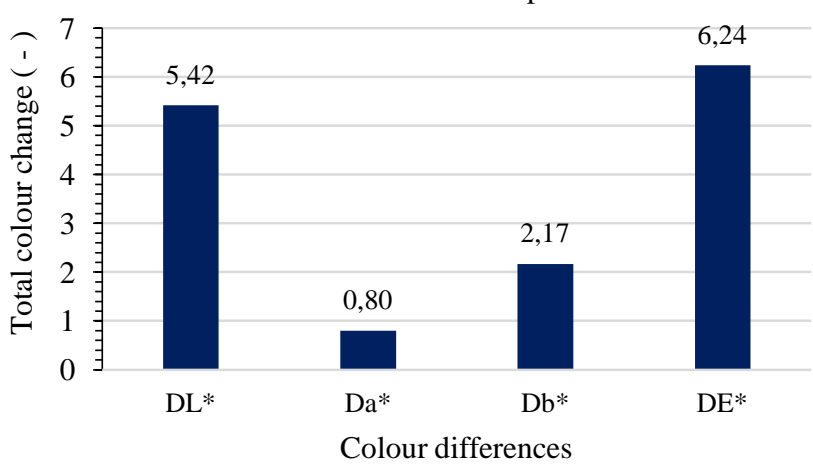

Fig. 6. Comparison of colour parameter differences 
Table 10. Correlation between measured parameters, FSW failure strength, FSTW - failure strain, EW - modulus of elasticity, $W-$ wheat straw pellets

\begin{tabular}{|c|c|c|c|c|c|c|c|c||}
\hline & $\boldsymbol{L}^{*} \boldsymbol{W}$ & $\boldsymbol{a}^{*} \boldsymbol{W}$ & $\boldsymbol{b}^{*} \boldsymbol{W}$ & $\boldsymbol{h}^{\circ} \boldsymbol{W}$ & $\boldsymbol{C}^{*} \boldsymbol{W}$ & $\boldsymbol{F S T W}$ & $\boldsymbol{F S W}$ & $\boldsymbol{E W}$ \\
\hline $\mathbf{L}^{*} \mathbf{W}$ & 1 & & & & & & & \\
\hline $\mathbf{a}^{*} \mathbf{W}$ & $\mathbf{- 0 . 6 6 4}$ & 1 & & & & & & \\
\hline $\mathbf{b}^{*} \mathbf{W}$ & 0.342 & 0.230 & 1 & & & & & \\
\hline $\mathbf{h}^{\circ} \mathbf{W}$ & $\mathbf{0 . 8 1 0}$ & $-\mathbf{0 . 9 3 2}$ & 0.136 & 1 & & & & \\
\hline $\mathbf{C}^{*} \mathbf{W}$ & 0.277 & 0.309 & $\mathbf{0 . 9 9 7}$ & 0.054 & 1 & & & \\
\hline FSTW & -0.302 & 0.354 & 0.273 & -0.279 & 0.300 & 1 & & \\
\hline FSW & 0.241 & -0.050 & 0.330 & 0.163 & 0.318 & $\mathbf{0 . 7 4 9}$ & 1 & \\
\hline $\mathbf{E W}$ & $\mathbf{0 . 5 3 6}$ & $\mathbf{- 0 . 5 2 6}$ & -0.216 & 0.466 & -0.259 & -0.183 & 0.462 & 1 \\
\hline
\end{tabular}

Table 11. Correlation between measured parameters, FSM failure strength, FSTM - failure strain, EM - modulus of elasticity, $M-$ mixed straw pellets

\begin{tabular}{|c|c|c|c|c|c|c|c|c||}
\hline & $\boldsymbol{L}^{*} \boldsymbol{M}$ & $\boldsymbol{a}^{*} \boldsymbol{M}$ & $\boldsymbol{b}^{*} \boldsymbol{M}$ & $\boldsymbol{h}^{\circ} \boldsymbol{M}$ & $\boldsymbol{C}^{*} \boldsymbol{M}$ & $\boldsymbol{F S T M}$ & $\mathbf{F S M}$ & $\boldsymbol{E M}$ \\
\hline $\mathbf{L}^{*} \mathbf{M}$ & 1 & & & & & & & \\
\hline $\mathbf{a}^{*} \mathbf{M}$ & -0.337 & 1 & & & & & & \\
\hline $\mathbf{b}^{*} \mathbf{M}$ & $\mathbf{0 . 6 5 4}$ & -0.110 & 1 & & & & & \\
\hline $\mathbf{h}^{\circ} \mathbf{M}$ & $\mathbf{0 . 6 1 4}$ & $\mathbf{- 0 . 8 3 3}$ & $\mathbf{0 . 6 2 9}$ & 1 & & & & \\
\hline $\mathbf{C}^{*} \mathbf{M}$ & $\mathbf{0 . 6 4 6}$ & -0.078 & $\mathbf{0 . 9 9 9}$ & $\mathbf{0 . 6 0 4}$ & 1 & & & \\
\hline FSTM & -0.482 & 0.453 & -0.333 & $\mathbf{- 0 . 6 1 9}$ & -0.318 & 1 & & \\
\hline FSM & -0.478 & 0.349 & -0.059 & -0.361 & -0.048 & $\mathbf{0 . 7 9 3}$ & 1 & \\
\hline EM & -0.200 & 0.239 & 0.359 & 0.007 & 0.366 & 0.230 & $\mathbf{0 . 7 2 6}$ & 1 \\
\hline \hline
\end{tabular}

\section{CONCLUSION}

The main result of the work was finding out the correlation between compression and colour parameters.

The effect of the failure strength, the failure strain and modulus of elasticity on the colour were determined and correlated only on the moderate level. The moderate positive and negative correlation at the significant level 0.05 was achieved between compression parameter modulus of elasticity of the wheat pellets (EW) and the colour parameter $L^{*}$ and $a^{*}$ of the wheat pellets (correlation coefficients 0.536 and -0.526 respectively) and the negative moderate correlation was achieved between failure strain of the mixed pellets (FSTM) and the colour parameter $h^{\circ}$ of the mixed pellets (correlation coefficient -0.619). The wheat pellet compressive parameters were better than the mixed pellets. The failure strength of the wheat pellets was greater than the failure strength of mixed pellets. The color parameters of both sorts of pellets were very similar.

The pellets made from the wheat straw achieved the values of the colour coordinates $L^{*}=55.279, a^{*}=4 ., 106$ and $b^{*}=$ 22.186 and the pellets made from mixed straw values $L^{*}=$ $59.520, a^{*}=3.463$ and $b^{*}=20.961$. The colour of $a^{*}$ coordinate was close to a reddish colour and $b^{*}$ coordinate was close to a yellowish colour. The hue angle of the wheat straw pellet was $h^{\circ}$ $=79.405^{\circ}$ and chroma $C^{*}=22.568$. The hue angle of the mixed straw pellet was $h^{\circ}=80.451$ and chroma $C^{*}=21.255$. The differences of the colour between both sorts of the pellets reached values $\Delta L^{*}=5.419, \Delta a^{*}=0.803, \Delta b^{*}=2.169$ and $\Delta E=$ 6.235 . The pellets were distinguishable also by the eye, because $\Delta E$ was greater than 1 . These measured colour parameters of the pellets we can apply only on the tested pellets.

ACKNOWLEDGEMENT: This publication was supported by the Operational Program Integrated Infrastructure within the project: Demand-driven research for the sustainable and innovative food, Drive4SIFood 313011V336, co-financed by the European Regional Development Fund.

\section{REFERENCES}

Frodeson, S., Lindén, P., Henriksson, G. and Berghel, J. (2019a). Compression of Biomass Substances - A Study on Springback Effects and Color Formation in Pellet Manufacture. Applied Sciences, 9, 4302, 1 - 15, doi:10.3390/app9204302.

Frodeson, S., Henriksson, G. and Berghel, J. (2019b). Effects of moisture content during densification of biomass pellets, focusing on polysaccharide substances. Biomass and Bioenergy 122, 322-330.

Gözlekçi, Ş., Saraçoğlu, O., Onursal, E. and Özgen, M. (2011) Total Phenolic Distribution of Juice, Peel, and Seed Extracts of Four Pomegranate Cultivars. Pharmacognosy Magazine, 7, 161 $-164$.

Chan, L. W., Chan, W. Y., Heng, P. W. S. (2001). An improved method for the measurement of colour uniformity in pellet coating. International Journal of Pharmaceutics, 213, 63 - 74.

Júnior, M. C. A., Andrade, J. S. and Costa, S.S. (2016). Biochemical Changes of Cubiu Fruits (Solanum sessiliflorum Dunal, Solanaceae) According to Different Tissue Portions and Ripening Stages, Food and Nutrition Sciences, 7, 1191 1219.

Koprivica, G., Mišljenović, N., Lević, L., Jokanović, M., Jevrić, L. (2011). Effect of process parameters on the colour of apple osmotically dehydrated in sugar beet molasses, 15, 4, 223 226.

Larsson, S, H., Samuelsson, R. (2017). Prediction of ISO 178311:2015 mechanical biofuel pellet durability from single pellet characterization. Fuel Processing Technology 163, 8 -15.

León, K., Mery, D., Pedreschi, F., León, J. (2006). Colour measurement in $\mathrm{L}^{*} \mathrm{a} * \mathrm{~b} *$ units from RGB digital images. Food Research International, $391084-1091$.

McGuire, R.G. (1992) Reporting of Objective Colour Measurements. HortScience, 27, 1254-1255.

http://dx.doi.org/10.4103/0973-1296.80681

Pavkov, I., Stamenković, Z., Radojcin, M., Krstan, K., Bikić, S. (2019) Air drying of blueberry fruits: drying kinetics, mathematical modeling and physical properties, Journal on Processing and Energy in Agriculture, 23, 4, 151 - 157.

Pegoretti, H. J., Chaves, D. M., Vidaurre, G., P.

Brocco, V. F., Souza, D. P., and Protásio, T. P. (2019). Colorimetry of pellets produced with eucalyptus and coffee cultivation residues and their relationship to quality standards. Sci. For., Piracicaba, 47, 121, 114 - 124.

http://dx.doi.org/10.18671/scifor.v47n121.11

Radojčin, M., Babić, M., Babić, L., Pavkov, I., Stojanović, Č. (2010). Colour parameters change of quince during combined drying. Journal on Processing and Energy in Agriculture, 14, 2, $81-84$.

Radojčin, M., Babić, M., Babić, L., Pavkov, I., Stamenković, Z. (2013). Influence of different pretreatments on the colour of dried pears. Journal on Processing and Energy in Agriculture $17,4,176-179$.

Vukmirović,D., Ivanov, D., Čolović, R., Kokić, B., Lević, J. (2010). Effect of steam conditioning on physical properties of pellets and energy consumption in pelleting process. Journal on Processing and Energy in Agriculture, 14, 2, 106 - 108.

Received: 02. 03. 2021.

Accepted: 31. 03. 2021. 